\title{
CT-based and morphological comparison of glenoid inclination and version angles and mineralisation distribution in human body donors
}

Nabil Serrano ${ }^{1}$, Marc Kissling ${ }^{11}$, Hannah Krafft ${ }^{3}$, Karl Link ${ }^{3,4}$, Oliver Ullrich ${ }^{3}$, Florian M. Buck ${ }^{5}$, Sandra Mathews ${ }^{1}$, Steffen Serowy ${ }^{6}$, Dominic Gascho ${ }^{7}$, Patrick Grüninger ${ }^{8}$, Paolo Fornaciari ${ }^{9}, 10$, Samy Bouaicha ${ }^{9}$, Magdalena Müller-Gerbl ${ }^{2}$, Frank-Jakobus Rühli ${ }^{1 *+}$ and Elisabeth Eppler $2,6,11^{*+}$

\begin{abstract}
Background: For optimal prosthetic anchoring in omarthritis surgery, a differentiated knowledge on the mineralisation distribution of the glenoid is important. However, database on the mineralisation of diseased joints and potential relations with glenoid angles is limited.

Methods: Shoulder specimens from ten female and nine male body donors with an average age of 81.5 years were investigated. Using 3D-CT-multiplanar reconstruction, glenoid inclination and retroversion angles were measured, and osteoarthritis signs graded. Computed Tomography-Osteoabsorptiometry (CT-OAM) is an established method to determine the subchondral bone plate mineralisation, which has been demonstrated to serve as marker for the long-term loading history of joints. Based on mineralisation distribution mappings of healthy shoulder specimens, physiological and different CT-OAM patterns were compared with glenoid angles.
\end{abstract}

Results: Osteoarthritis grades were $0-\mathrm{I}$ in $52.6 \%$ of the 3D-CT-scans, grades II-III in 34.3\%, and grade IV in 13.2\%, with in females twice as frequently (45\%) higher grades (III, IV) than in males (22\%, III). The average inclination angle was $8.4^{\circ}$. In glenoids with inclination $\leq 10^{\circ}$, mineralisation was predominantly centrally distributed and tended to shift more cranially when the inclination raised to $>10^{\circ}$. The average retroversion angle was $-5.2^{\circ}$. A dorsally enhanced mineralisation distribution was found in glenoids with versions from $-15.9^{\circ}$ to $+1.7^{\circ}$. A predominantly centrally distributed mineralisation was accompanied by a narrower range of retroversion angles between $-10^{\circ}$ to $-0.4^{\circ}$.

\footnotetext{
* Correspondence: frank.ruehli@iem.uzh.ch; elisabeth.eppler@ana.unibe.ch

${ }^{\dagger}$ Frank-Jakobus Rühli, Elisabeth Eppler are Shared Senior authorship.

${ }^{1}$ Institute of Evolutionary Medicine (IEM), University of Zurich, Zurich,

Switzerland

${ }^{2}$ Musculoskeletal Research, Department of Biomedicine, University of Basel, Basel, Switzerland

Full list of author information is available at the end of the article
}

(c) The Author(s). 2021 Open Access This article is licensed under a Creative Commons Attribution 4.0 International License, which permits use, sharing, adaptation, distribution and reproduction in any medium or format, as long as you give appropriate credit to the original author(s) and the source, provide a link to the Creative Commons licence, and indicate if changes were made. The images or other third party material in this article are included in the article's Creative Commons licence, unless indicated otherwise in a credit line to the material. If material is not included in the article's Creative Commons licence and your intended use is not permitted by statutory regulation or exceeds the permitted use, you will need to obtain permission directly from the copyright holder. To view a copy of this licence, visit http://creativecommons.org/licenses/by/4.0/ The Creative Commons Public Domain Dedication waiver (http://creativecommons.org/publicdomain/zero/1.0/) applies to the data made available in this article, unless otherwise stated in a credit line to the data. 
Conclusions: This study is one of the first to combine CT-based analyses of glenoid angles and mineralisation distribution in an elderly population. The data set is limited to 19 individuals, however, indicates that superior inclination between $0^{\circ}$ and $10^{\circ}-15^{\circ}$, and dorsal version ranging between $-9^{\circ}$ to $-3^{\circ}$ may be predominantly associated with anterior and central mineralisation patterns previously classified as physiological for the shoulder joint. The current basic research findings may serve as basic data set for future studies addressing the glenoid geometry for treatment planning in omarthritis.

Keywords: Shoulder joint, 3D-CT, CT-OAM, Inclination angle, Glenoid anteversion, Glenoid retroversion, Bone mineralization

\section{Background}

Osteoarthritis is one of the most common diseases worldwide, causing pain and severe restrictions of the range of motion and quality of life, particularly in the elderly [39, 52, 54]. Progressive disease causes extensive morphological changes in articular cartilage and subchondral bone, which may result in narrowed joint gap, subchondral sclerosis, osteophytes and deformation of the glenoid including alterations of glenoid angles. An ideal range is not clearly defined to date, but the geometry of the glenoid may predispose for alterations [15, $17,36,39,55]$. To achieve an optimal treatment outcome, e.g., positioning of the prosthetic glenoid component, a profound knowledge on optimal geometry, particularly the glenoid angles, and bone mineralisation is essential [3, 15-17, 29, 33, 39].

More than 30 years ago, Computed Tomography Osteoabsorptiometry (CT-OAM) was established [38] to determine the mineralisation distribution of the subchondral bone plate, which has been demonstrated as suitable marker for the long-term loading history of manifold articulations in animal species and humans, e.g. $[9,32,40]$, including healthy $[18,28,56-58]$, and osteoarthritic $[46,49]$ shoulder joints. In the present study, we used CT-based methods to compare the mineralisation distribution of the glenoid with inclination and version angles in order to expand the data set on physiological and different geometry and mineralisation patterns of the shoulder joint as an entity [58].

For that purpose, measurements of both, glenoid and humeral head were performed by 3D-CT multiplanar reconstructions to compare the present data with those from previous studies [35, 56-58]. Further, osteoarthritic alterations were graded using 3D-CT reconstructions. As a next step, inclination and version angles were individually compared based on CT-measurements with the mineralisation distribution, and discrepancies between angles and mineralisation patterns further analysed for morphological and radiological signs of osteoarthritis. Finally, a range of inclination and ante-/retroversion angles was defined, which contained the majority of physiological mineralisation distribution patterns as previously defined [45].

\section{Methods and material Body donors}

The study was performed on shoulder specimens from ten female and nine male body donors with an average age of 81.5 years ( \pm 11.3 years, range: $60-98$ years, median: 85 years) from the body donation programme of the Institute of Anatomy of the University of Zurich [21] according to the Federal Act on Research involving Human Beings (Human Research Act, HRA) of 1 January 2014 [20] and the Guidelines of the Swiss Academy of Medical Sciences, updated 2014 [22, 23] as described [35]. The bodies served for the dissection course of 2nd year medical bachelor students during the curricular years 2013/2014, 2014/2015, and 2015/2016.

\section{Dissection and morphological classification of the shoulder specimens}

The gleno-humeral joint was exposed by the deltopectoral approach as described [35]. We deliberately did not exclude specimens with signs of pathologies to create a representative data set for an aged study population. Glenoid and humeral head were graded by three experienced shoulder surgeons using the same quadrants as for CT-OAM (see below) according to the Outerbridge classification [2, 47, 51], adapted for body donor specimens (Figs. 1 and 2): Grades 0 (normal cartilage) and I were merged to grade I since grade I chondral lesions characterized by softening and swelling [51], often requiring tactile feedback [47] were difficult to differentiate in formalinfixated donor samples. We also assumed grade I lesions in this aged cohort as physiological. Grade II lesions were characterized by partial thickness defects with visually detectable softening, blistering, small fissures and fibrillations without contact to the subchondral bone, grade III by larger cartilage fissures and deep ulcerations, sometimes reaching the subchondral bone, and grade IV by erosions exposing the subchondral bone [2, 47, 51]. Discrepancies were discussed by an experienced anatomy lecturer and two young physicians for final decision.

\section{CT scan acquisition}

CT scans were acquired intended for virtual teaching prior to the dissection course at the Institute of Forensic 

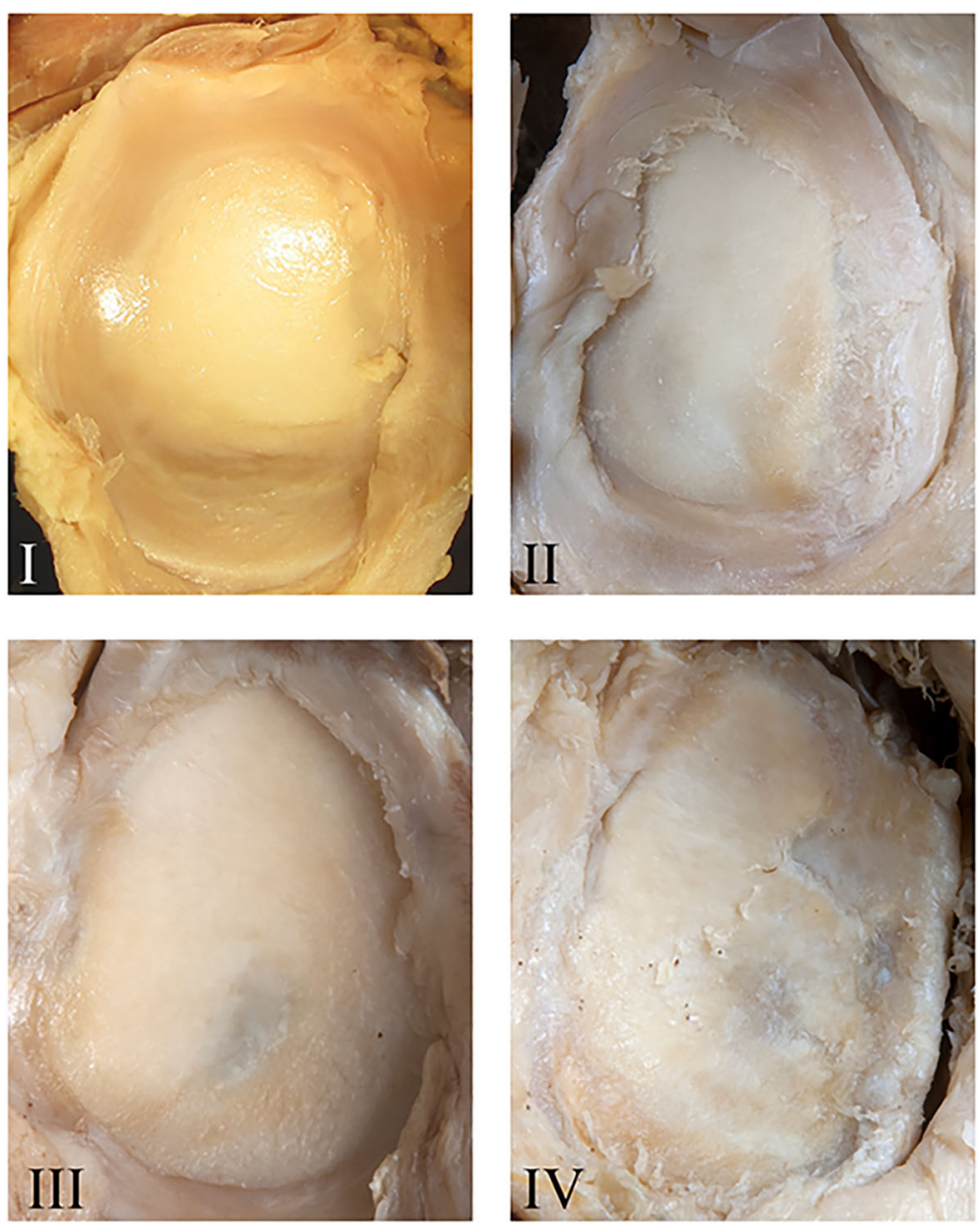

Fig. 1 Representative images of osteoarthritis grades I, II, III and IV in dissected glenoids

Medicine of the University of Zurich using a 128-slice CT scanner (Somatom Definition Flash, Siemens Healthcare, Forchheim, Germany). The scan parameters were $120 \mathrm{kV}$ and 500 reference mAs using dose modulation CAREdose4D ${ }^{\text {mix }}$ (Siemens Healthcare) as described [14]. Raw data were reconstructed with a slice thickness of $0.6 \mathrm{~mm}$ and an increment of $0.4 \mathrm{~mm}$ using a hard kernel (B60) for 3D-analysis and a soft kernel (B30) for CTOAM. The size of the reconstruction field of view was adjusted for separate reconstructions of left and right shoulder. DICOM files were transferred to OSIRIX ${ }^{\mathrm{Tx}}$ medical imaging viewer (Pixmeo SARL, Bernex, Switzerland).

\section{D-CT reconstruction of the gleno-humeral joint}

The osseous window enabled to eliminate all soft tissue. To obtain an unobstructed view of each articular surface, either humerus, or scapula and clavicle were extracted. For optimal selection and extraction of a bone, the region of interest segmentation was set from 300 to
2'000 Hounsfield units (HU). The volume content was erased, and the 3D volume rendering option rendered a 3D image. The resulting articular surface was displayed with two different pre-sets, i.e., "Bone CT glossy" and "Basic with low contrast". Data were exported as DICOM-series at highest quality scale for best image, for the glenoid in a sagittal view and for the humeral head in two $180^{\circ}$ orientations, i.e., anterior and lateral view (horizontal and vertical).

\section{D-CT-based analyses of joint surfaces}

In order to compare the data set with previous studies, height and width of the joint surfaces were measured. The glenoid (Fig. 3A) was measured according to Martin and Saller [34] as commonly used intraoperatively and adapted to our specimens [35]. Height, width (Fig. 3B) and depth (Fig. 3C) of the humeral head were measured using established referencing points, whereby osteophytes were strictly avoided to prevent overestimation of the surface area [26]. 

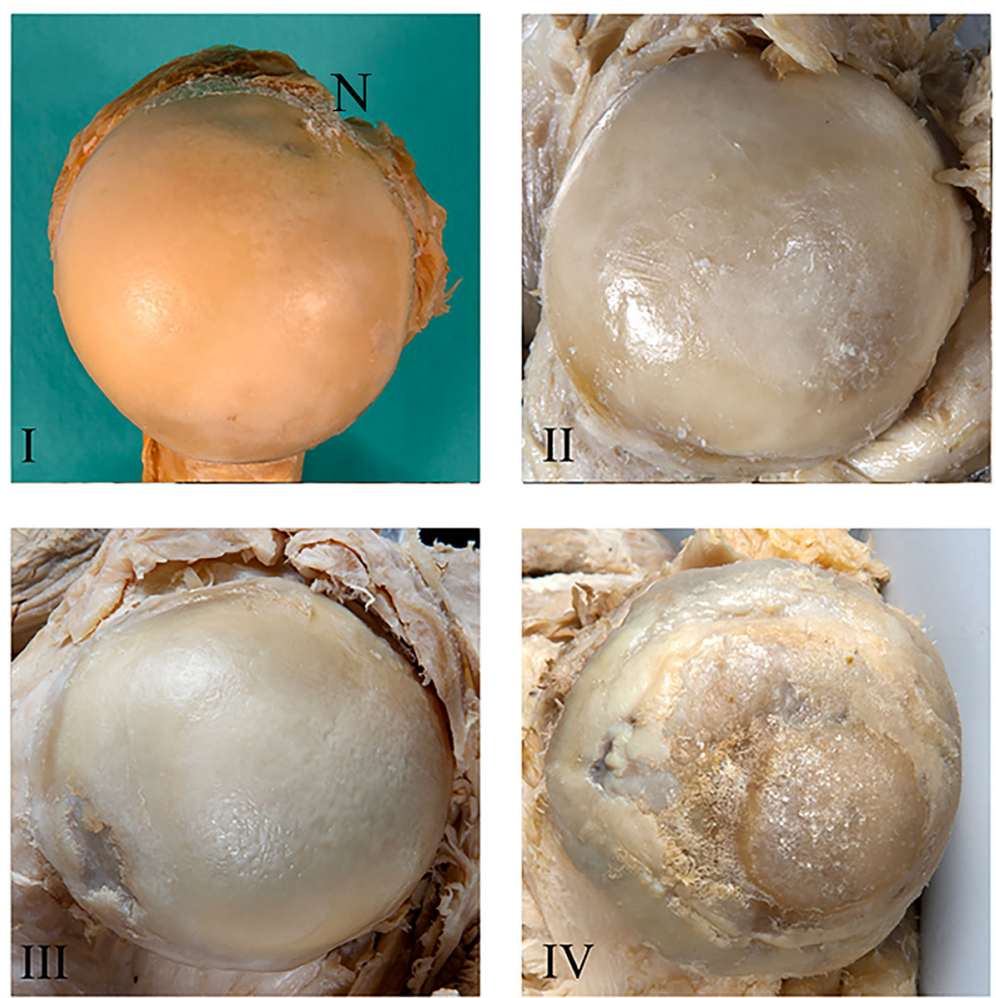

Fig. 2 Representative images of osteoarthritis grades II II, III and IV in dissected humeral heads. (I) N points to the notch in the humeral head formed by the tendon of the long head of the biceps used as a reference for CT-OAM and morphological inspections

\section{D-CT measurements of inclination and ante - /retroversion angles}

In the 3D-multiplanar reconstruction mode (Fig. 3D,E), a plane of the scapula was defined by the midpoint of the root of the scapular spine, the center of the glenoid, and the most distal point of the inferior scapula angle as described $[6,35]$. Inclination was determined in the coronal plane according to Churchill et al. [7]: The angle $\gamma$ was measured (Fig. 3D) and the inclination angle $\alpha$ calculated by the formula: $\alpha=\gamma-90^{\circ}$ as described [35]. Positive angles describe superior inclination [15]. The ante-/retroversion was determined in the transversal plane according to Friedman method [13]: The angle $\delta$ was measured (Fig. 3E) and the version angle $\beta$ calculated by the formula: $\beta=\delta-90^{\circ}$ as described [35]. Negative values indicate retroversion, positive values anteversion $[15,35]$.

\section{D-CT -based analyses of osteoarthritis signs}

For analysis of osteoarthritis signs in the gleno-humeral joints using 3D-CT (Fig. 3), an osteoarthritis grading score was created based on the Kellgren-Lawrence Score [25] and adapted to body donors considering the Larsen [30] and Samilson and Prieto [44] radiological classifications (Table 1).

\section{Bone mineralisation analysis by CT-osteoabsorptiometry (CT-OAM)}

CT-OAM analyses were performed as established for healthy shoulders [45, 56-58]. In brief, DICOM data sets were analysed using an image analysis system (ANALYZE, version 7.4, Biomedical Imaging Resource, Mayo Foundation, Rochester, MN, USA). The subchondral bone plate was isolated by segmentation of CT scans. By means of maximum intensity projection, for each pixel until a depth of $3 \mathrm{~mm}$, values with the highest density were projected onto the surface. Threshold values were selected according to previous studies to be $<200$ to $>1200 \mathrm{HU}$ [28]. To display the mineralisation distribution, data were false colour-encoded and superimposed on the identical 3Dreconstructed joint (Fig. 4A,B) as described [57]. Areas of highest mineralisation distribution were identified as "central", "cranial", "caudal", "ventral" or "dorsal" by quadrants of the articular surfaces (Fig. 4C,D) similar to previous work $[57,58]$. The mineralisation distribution patterns (Fig. 4) were compared with those of previous studies from our group in healthy shoulders for typical criteria of physiological distributions $[28,45]$, i.e., predominantly central and anterior > posterior as described [45]. Mineralisation patterns differing from these physiological patterns were classified as "different" or "non-physiological", respectively. 

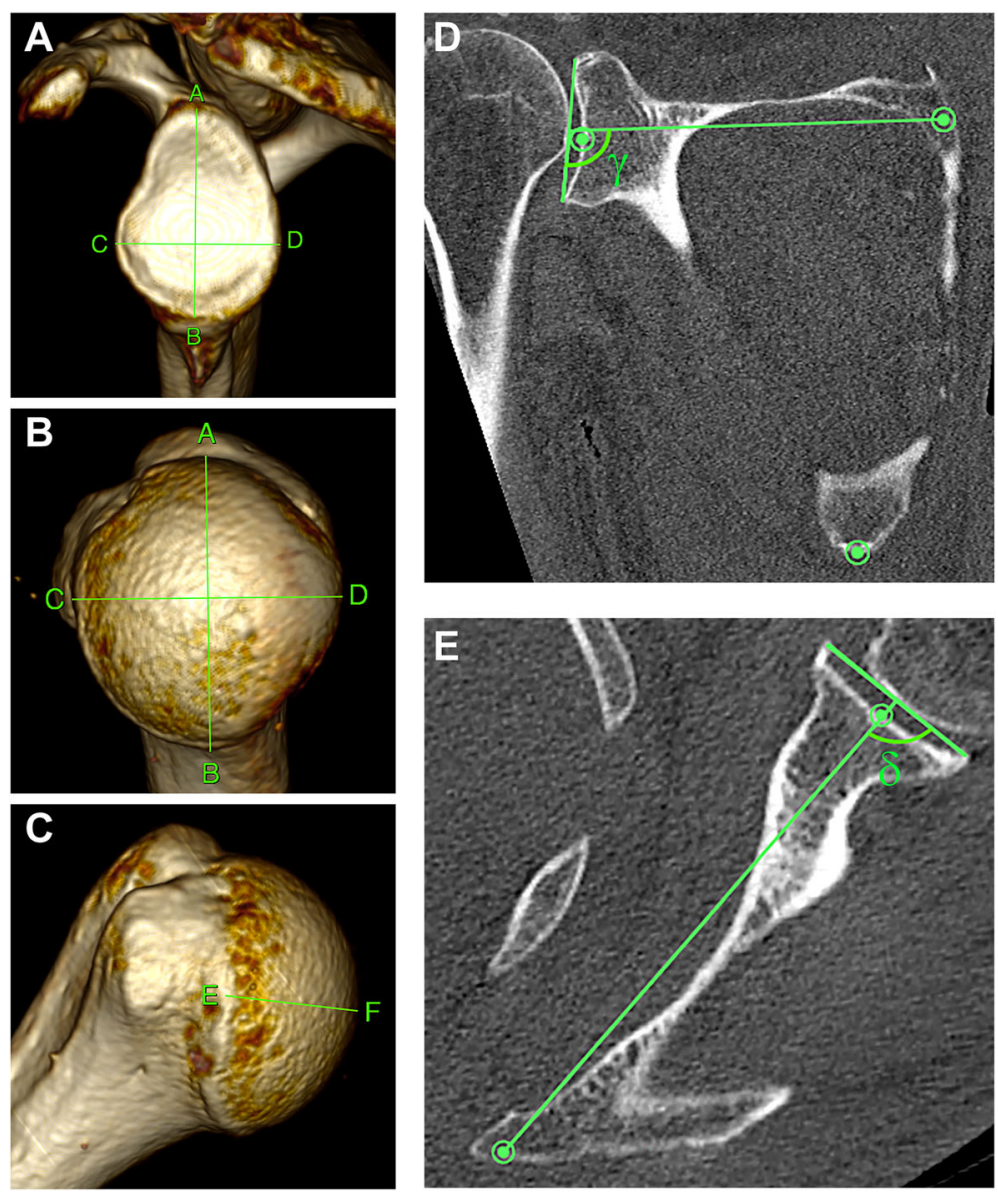

Fig. 3 2D-CT images of 3D-CT reconstructions of the articular surfaces of a left shoulder. A Height and width of the glenoid measured as described [35]: a line drawn from the most cranial (A) to the most caudal point (B) of the glenoid cavity, and another line from the most ventral (C) to the most dorsal point (D) of the glenoid rim. B Height and width of the humeral head measured using established landmarks [26]: the greater tubercle as reference to place the uppermost point $(\mathbf{A})$ at the edge of the smooth articular surface and a perpendicular line was drawn to the lowest (B) point. C The depth of the humeral head measured using established landmarks [26]: the lesser tubercle as reference for the most anterior point $(\mathbf{F})$, from this, a perpendicular line was drawn to the most posterior point $(\mathbf{E})$ of the smooth articular surface. D The inclination angle a was determined in the coronal plane using reference points (green) as described [7, 35]: a line was drawn through the root of the scapular spine to the midpoint of the glenoid cavity, and a second line through the most cranial and caudal points (see $\mathbf{A}$, reference points $\mathbf{A}$ and $\mathbf{B}$ ) of the glenoid rim. Angle $\gamma$ was measured between the axes of these two lines in caudal direction, and the inclination angle a calculated: $\mathbf{a}=\gamma-90^{\circ}$. E The ante-/retroversion angles $\beta$ were determined in the transversal plane using reference points (green) as described [13, 35]: a line was drawn through the root of the scapular spine to the midpoint of the glenoid cavity, and a second line through the most posterior and anterior points (see $\mathbf{A}$, reference points $\mathbf{C}$ and $\mathbf{D}$ ) of the glenoid rim. Angle $\delta$ was measured between the axes of these two lines in sagittal direction and angle $\beta$ calculated: $\beta=\delta-90^{\circ}$

\section{Comparison of inclination and ante-/retroversion angles with mineralisation distribution}

As a next step, the mineralisation distribution was compared with inclination and version angles. Samples were grouped as described (Table 2).

\section{Data analysis and statistics}

Quantitative measurements were expressed as absolute values, mean ( \pm standard deviation) and median. Qualitative variables were compared as described and the positive results calculated as percentage.

\section{Results}

\section{Study population and 3D-CT specimen characteristics}

Glenoid and humeral head sizes from ten female and nine male body donors were similar to our ([35] with further references) and other published data [26] so that we considered the cohort as representative. Similarly, all parameters were smaller in females (Supplement 1). In $52.6 \%$ of CT scans, osteoarthritis grades 0-I were observed, in 34.3\% grades II-III, and in $13.2 \%$ grade IV (Table 3 ). Respecting potential post-mortem changes, data analysis was restricted to glenoid malformation $(n=8)$, osteophytes $(n=14)$, and narrowed joint gap $(n=11)$ in both sides together. 
Table 1 Grading score of 3D-CT scans of the gleno-humeral joint

\begin{tabular}{|c|c|c|c|}
\hline Points & Kellgren-Lawrence Score [25] & Samilson and Pietro Classification [44] & Larsen Classification [30] \\
\hline 0 & absence of signs of osteoarthritis & no exostosis & normal conditions, marginal bone deposits \\
\hline 1 & $\begin{array}{l}\text { definite osteophytes and possible joint } \\
\text { space narrowing }\end{array}$ & $\begin{array}{l}\text { inferior humeral and/or glenoid exostosis } \\
<3 \mathrm{~mm} \text { in height }\end{array}$ & $\begin{array}{l}\text { definite early abnormality, erosion and joint } \\
\text { space narrowing present }\end{array}$ \\
\hline 2 & $\begin{array}{l}\text { moderate multiple osteophytes, definite } \\
\text { narrowing of joint space, some sclerosis }\end{array}$ & $\begin{array}{l}\text { inferior humeral and/or glenoid exostosis } \\
\text { measuring 3-7 mm, and slight } \\
\text { gleno-humeral irregularity }\end{array}$ & $\begin{array}{l}\text { medium to severe destructive abnormality, } \\
\text { erosion and joint space narrowing present }\end{array}$ \\
\hline 3 & $\begin{array}{l}\text { large osteophytes, marked narrowing } \\
\text { of joint space, severe sclerosis }\end{array}$ & $\begin{array}{l}\text { inferior humeral and/or glenoid exostosis } \\
\text { measuring }>7 \mathrm{~mm} \text {, gleno-humeral joint } \\
\text { narrowing and sclerosis }\end{array}$ & $\begin{array}{l}\text { mutilating abnormality, gross bony } \\
\text { destruction, dislocation and ankylosis }\end{array}$ \\
\hline Maximum 9 points & Maximum 3 points & Maximum 3 points & Maximum 3 points \\
\hline
\end{tabular}

Established osteoarthritis classifications were considered [25, 30, 44]. Grade 0: no osteoarthritis signs, grade 1:1-2 points, grade 2: 3-4 points, grade 3: 5-7 points, grade 4: 8-9 points

Higher osteoarthritis grades were detected twice as frequently in females, i.e., $9 / 20$ shoulders $(45 \%$, grade III-IV) versus $4 / 18$ (22\%, grade III) in males (Table 4$)$.

\section{D-CT-measurements of glenoid angles}

The average inclination angle from male and female donors combined was $8.4^{\circ} \pm 4.9^{\circ}$ (range $0.5^{\circ}$ to $+19.8^{\circ}$, median: $7.8^{\circ}$ ), left $8.6^{\circ} \pm 5.0^{\circ}$ (range $0.5^{\circ}$ to $+19.8^{\circ}$, median: $7.9^{\circ}$ ), and right $8.2^{\circ} \pm 5.0^{\circ}$ (range $1.0^{\circ}$ to $+19.4^{\circ}$, median: $\left.7.8^{\circ}\right)$. The average ante-/retroversion angle from male and female donors combined was $-5.2^{\circ} \pm 4.2^{\circ}$ (range - $15.9^{\circ}$ to $+3.8^{\circ}$, median: $-4.9^{\circ}$ ), left $-4.8^{\circ} \pm 4.8^{\circ}$ (range $15.9^{\circ}$ to $+3.8^{\circ}$, median: $-3.8^{\circ}$ ), right $-5.6^{\circ} \pm 3.7^{\circ}$ (range $-14.3^{\circ}$ to $+1.6^{\circ}$, median: $-5.8^{\circ}$ ).

\section{CT-OAM analyses of glenoid mineralisation patterns}

In 19 left specimens, glenoids were classified as physiological mineralisation distribution (compare Figs. 4A and 5D) in vertical (eleven cases), and horizontal orientation (nine cases) according to published patterns [45]. Among the differing mineralisation patterns, enlarged areas of mineralisation were visible
A

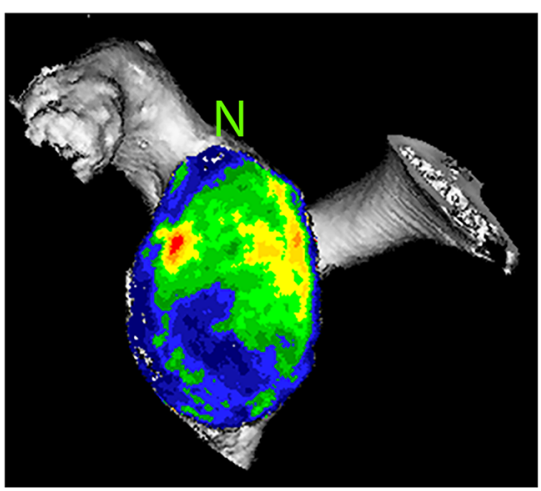

C

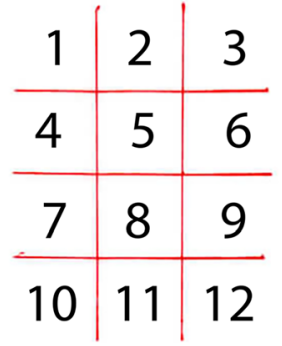

B

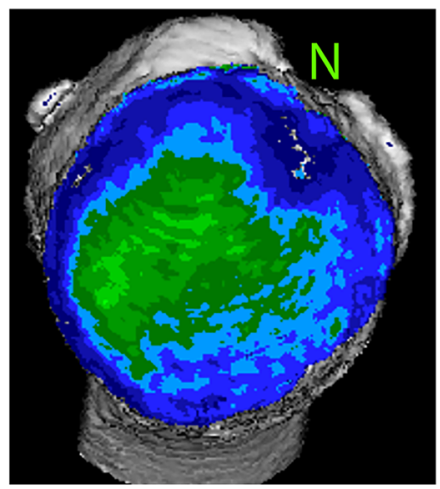

D

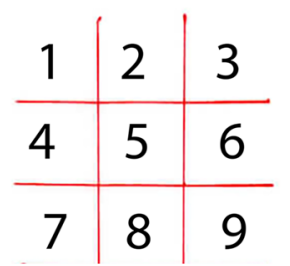

Fig. 4 Representative CT-OAM images showing mineral distribution of (A) glenoid, and (B) humeral head. CT-OAM false colour-encoded (black > red $>$ orange $>$ yellow $>$ bright green $>$ dark green $>$ blue $>$ violet, see: [57]) and superimposed on the identical 3-D-reconstructed joint. $\mathrm{N}$ points (A) to the most superior point of the glenoid, and (B) to notch in the humeral head formed by the tendon of the long head of biceps. (C, D) A grid was superimposed over the CT-OAM and morphology images to separate the articular surface in quadrants of glenoid (C) and humeral head (D) similar to previous work $[57,58]$ 
Table 2 Comparison of samples based on CT-mineralisation distribution and glenoid angles

\begin{tabular}{|c|c|c|}
\hline CT-based measurement & $\begin{array}{l}\text { physiological: central } \\
\text { and anterior > dorsal }\end{array}$ & $\begin{array}{l}\text { Different } \\
\text { mineralisation } \\
\text { pattern }\end{array}$ \\
\hline Inclination angle $\leq 10^{\circ}\left(15^{\circ}\right)$ & positive & negative \\
\hline $\begin{array}{l}\text { Ante-/retroversion angle } \\
\text { ranging between }-8^{\circ} \text { to }-4^{\circ}\end{array}$ & positive & negative \\
\hline \multicolumn{3}{|c|}{$\begin{array}{l}\text { Glenoid samples compared by their physiological mineralisation pattern (see } \\
\text { Figs. } 4 \text { and 5) according to Schulz et al. [45], and glenoid angles defined in the } \\
\text { order of magnitude of current literature }[12,15,16,19,24,35,41,42,48] \text {. In } \\
\text { selected cases, physiological inclination was expanded to } 15^{\circ} \text { in this aged } \\
\text { cohort. "Positive" defined as physiological CT-OAM-patterns and angles within } \\
\text { our defined physiological range or, as different CT-OAM-patterns and angles } \\
\text { outside this range. "Negative" defined as physiological CT-OAM patterns and } \\
\text { angles outside this range or, as different CT-OAM patterns and angles within } \\
\text { the range }\end{array}$} \\
\hline
\end{tabular}

cranial in five cases (63\%), caudal in three cases $(37 \%)$ (Fig. 6D), posterior in nine (90\%), and anterior in one (10\%) case (Fig. 6D). The corresponding humeral head showed grade IV erosion of the articular surface, which was partly congruent (Fig. 6F,H) to areas of mineralisation distribution considered as physiological (compare Figs. 4B and 5H), but partly to areas of reduced mineralisation distribution, particularly in the periphery.

In 19 right specimens, physiological mineralisation distributions were detected in twelve cases in vertical (Fig. 5C) and in seven cases horizontal orientation. Among the differing patterns, mineralisation was enhanced in five cases (71\%) more cranial, and in two (29\%) more caudal. Among the twelve differing patterns in horizontal orientation, in nine (75\%) individuals, the mineralisation was dorsally enhanced. In three cases (25\%), a different pattern was observed, e.g. diagonal (one case, not shown) or evenly distributed with moderate caudal shift (2 cases, see Fig. 6C). The corresponding humeral head showed pronounced osteoarthritic defects grade IV at the periphery of the articular surface, while the mineralisation was distributed predominantly centrally with some scattered maxima and, in the periphery, minima (Fig. 6E,G).

\section{Comparison of inclination angles and CT-OAM}

In 15/19 left and right glenoids (79\%), inclination angles within or outside our defined ranges (compare Table 2) were measured in agreement with correspondingly defined mineralisation patterns, i.e., physiological or different. These agreements were bilateral in 13 individuals,

Table 3 Summarised 3D-CT-based radiological osteoarthritis grades

\begin{tabular}{lllll}
\hline Grade $\mathbf{0}$ & Grade I & Grade II & Grade III & Grade IV \\
\hline $11 / 38$ & $9 / 38$ & $5 / 38$ & $8 / 38$ & $5 / 38$ \\
$(28.9 \%)$ & $(23.7 \%)$ & $(13.2 \%)$ & $(21.1 \%)$ & $(13.2 \%)$ \\
\hline
\end{tabular}

Grading of gleno-humeral osteoarthritis based on Kellgren-Lawrence Score [25], Larsen classification [30], and Samilson and Prieto radiological classification [44] (Table 1) and when expanded to $10.7^{\circ}$ in a physiological morphology (Fig. 5A,C), raised unilateral to $16 / 19$ right glenoids (84.2\%). In the remaining three cases of differences, inclination angles within our physiological range were combined with cranially enlarged mineralisation areas (Fig. 7C,G) whereby morphological alterations were detected in both, cranial (Fig. 7A) and caudal (Fig. 7A,E) quadrants.

On the left, an inclination of $15.9^{\circ}$ was detected in a glenoid with physiological mineralisation distribution and morphology (Fig. 5B,D), and bilateral radiological osteoarthritis grade 0 (data not shown). Three glenoids with inclinations angles within our range defined as physiological, showed mineralisation distributions outside the physiological pattern, one caudal (data not shown) and two cranial (Fig. 7D). Enlarged mineralisation areas were located to the neighbourhood of damaged cartilage, particular on the glenoid rim (Fig. 7D,H), while areas of comparably reduced mineralisation (Fig. 7D,H) were co-localised with destroyed areas (Fig. 7B,F). Some spots were completely congruent between morphology and CT-OAM.

\section{Comparison of ante-/retroversion angles and CT-OAM}

To a lesser extent, positive results (compare Table 2) were found for ante-/retroversion angles in 13/19 (69\%) right glenoids, with expanded margin in 15/19 (79\%). The four cases of disagreement were either due to retroversion $\left(-2.1^{\circ}\right)$ in a physiological mineralisation distribution, or to retroversion within the physiological range, but mineralisation different from our physiological pattern, in one case with even distribution, but some spots on the rim and mild signs of osteoarthritis (Fig. 5A, C), and in two cases osteoarthritis grade III (data not shown).

In 11/19 left shoulders (57.9\%), positive results (compare Table 2) were found, when expanding the range ($\left.9^{\circ}\right)$, in $13 / 19$ (68.4\%). The six cases of disagreement were due to one retroversion angle within our defined range in a glenoid with dorsally enhanced mineralisation and grade II osteoarthritis (data not shown). Angles outside the physiological range were measured in five glenoids with physiologic mineralisation distribution with corresponding morphology and predominantly low radiological osteoarthritis grades, respectively.

Table 4 Summarised 3D-CT-based radiological osteoarthritis grades sorted by sex

\begin{tabular}{llllll}
\hline & Grade $\mathbf{0}$ & Grade I & Grade II & Grade III & Grade IV \\
\hline male & $3 / 18$ & $9 / 18$ & $2 / 18$ & $4 / 18$ & $0 / 18$ \\
female & $8 / 20$ & $0 / 20$ & $3 / 20$ & $4 / 20$ & $5 / 20$ \\
\hline
\end{tabular}

Grading of gleno-humeral osteoarthritis sorted by sex based on KellgrenLawrence Score [25], Larsen classification [30], and Samilson and Prieto radiological classification [44] (Table 1) 


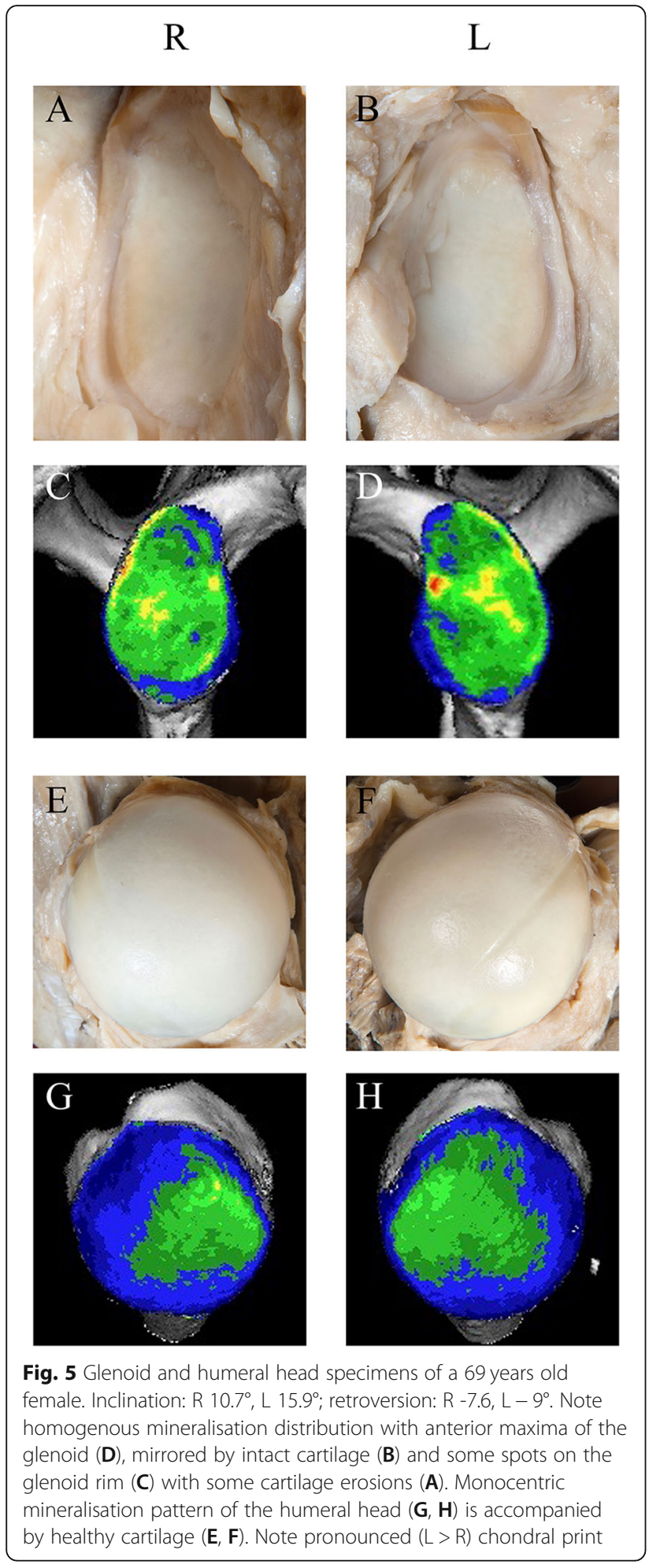

Determination of optimal ranges for inclination and ante - /retroversion angles

Based on the above results, a range of angles was searched covering on the one hand, a maximum of physiological mineralisation patterns (see Figs. 4A, 5D)
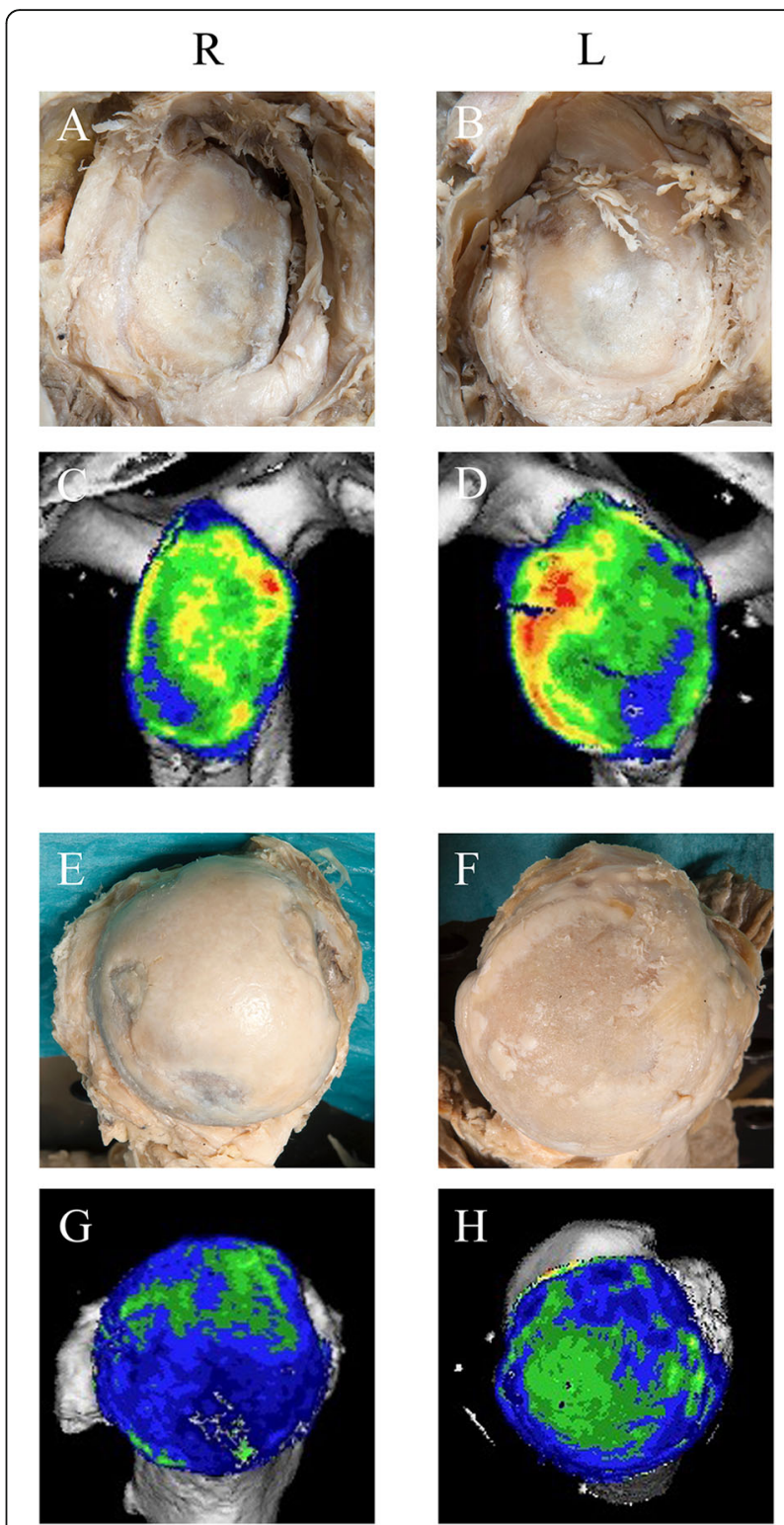

Fig. 6 Glenoid and humeral head specimens of a 74 years old male with pronounced signs of osteoarthritis $(\mathbf{A}, \mathbf{B})$. On the right (R), inclination $\left(7.1^{\circ}\right)$ and retroversion $\left(-2.7^{\circ}\right)$ with homogenously distributed mineralisation and a moderate caudal shift (C). On the left $(\mathrm{L})$, inclination $\left(10.7^{\circ}\right)$ and retroversion $\left(-9.5^{\circ}\right)$ combined with antero-caudal enhanced mineralisation (D). Both humeral heads with pronounced osteoarthritic defects grade IV in the dissected specimens $(\mathbf{E}, \mathbf{F})$, without $(\mathbf{G})$ or only partial $(\mathbf{H})$ congruency to mineralisation distribution

as published $[28,45]$, and on the other hand, a minimum of different patterns (see Table 2). In cases of morphological osteoarthritic appearance (Fig. 6B,D), the original range for inclination $\leq 10^{\circ}$ was applied. By iterative recalculations of test ranges, a superior inclination of $\leq 10^{\circ}$ was defined as optimal (Fig. 8A,B), which is within the order of magnitude of current literature, e.g., ([12, 15, 


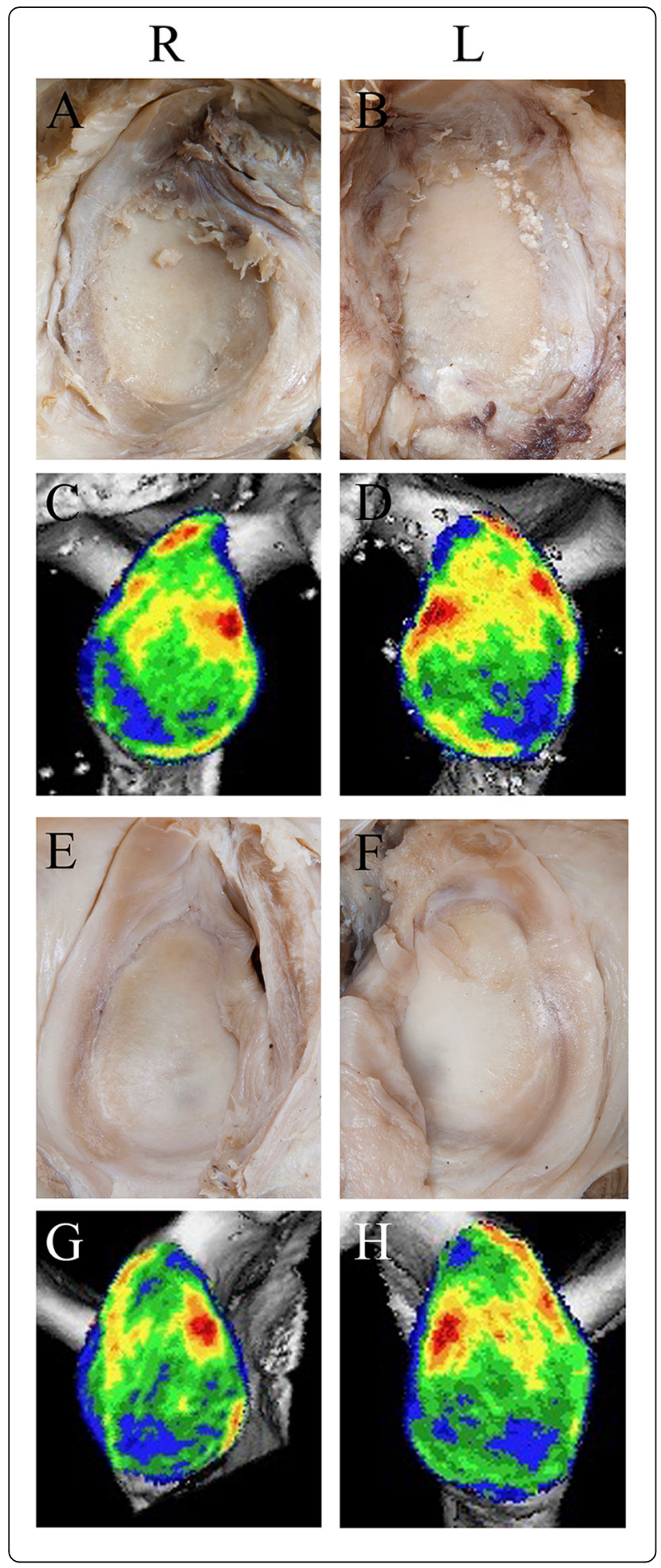

Fig. 7 Mineralisation distribution in glenoids with inclination angles $<10^{\circ}$. A-D 73 years old male (inclination: $R 7.8^{\circ}, \mathrm{L} 3.3^{\circ}$; retroversion: $R$ $\left.-6.9^{\circ}, \mathrm{L}-6.7^{\circ}\right) . \mathbf{C}, \mathbf{D}$ On both sides, in addition to anterior mineralisation, density maxima in cranial and dorsal quadrants corresponding to cartilage defects $(\mathbf{A}, \mathbf{B})$. Cartilage thinning in the anterior, more caudal quadrants $(\mathbf{A}, \mathbf{B})$ mirrored by CT-OAM $(\mathbf{C}, \mathbf{D})$. Some spots along the glenoid rim, probably osteophytes. E-H 72 years old male (inclination: $R 7.6^{\circ}, \mathrm{L} 2.9^{\circ}$; retroversion $R-1.7^{\circ}, L-0.4^{\circ}$ ). In the left shoulder, note higher mineralisation in cranial quadrants $(\mathbf{H})$ and cartilage lesion $(\mathbf{F})$. Some spots along the glenoid rim probably osteophytes

$24,35,53]$, with further references). Selected cases at the margins of this range were individually inspected for healthy appearance (e.g., Fig. 5), and the proposed range expanded to $\leq 15^{\circ}$ for recalculation. For ante-/retroversion angles, the test range was defined between $-8^{\circ}$ to $4^{\circ}$ (Fig. 8C,D) in the order of magnitude of current literature $[15,19,24,27,35,48]$. Selected cases at the margins of this range were inspected, and if suitable, the proposed range was expanded by $\pm 1^{\circ}$.

\section{Discussion}

In this interdisciplinary study, we examined shoulder specimens from ten female and nine male body donors with an average age of 81.5 years, which is representative for the elder population like our previous study [35]. Also the larger glenoids in males than females were comparable to preceding studies in Middle Europe and America including our own [35] whereby in the present study, glenoid sizes were moderately larger. Also humeral head size was similar to the normal cohort in a previous study [26], which attributed their higher values achieved to improved accuracy of 3D-CTreconstruction. Thus, our study cohort is comparable to recent studies using 3D-CT, however, data of 19 donors are a limitation.

The average inclination angle in male and female donors combined was $8.4^{\circ}$, which is within the order of magnitude of current literature, e.g., ([15, 24, 31, 35, 53], with further references). In our previous study on a similar cohort [35], mean inclination of $13^{\circ}$ was similar to $12^{\circ}$ in predominantly female postoperative patients [16]. Our current findings are similar to osteoarthritic individuals $\left(7.6^{\circ}\right)$ in a study comparing pathologies [8] with higher inclination angles $\left(13.6^{\circ}\right)$ in massive rotator cuff tears. Based on the literature (see above), we found inclination angles $\leq 10^{\circ}$ in glenoids with mineralisation distribution patterns considered as healthy [45], frequently combined with healthy morphology and low 3D-CT osteoarthritis gradings. In agreement, high inclination was recently grouped as $\geq 10^{\circ}$, low inclination between $0^{\circ}$ to $10^{\circ}$ and no inclination $\leq 0^{\circ}$ [39].

Simon and co-workers [46] used CT-OAM to analyze glenoid component loosening in total shoulder 


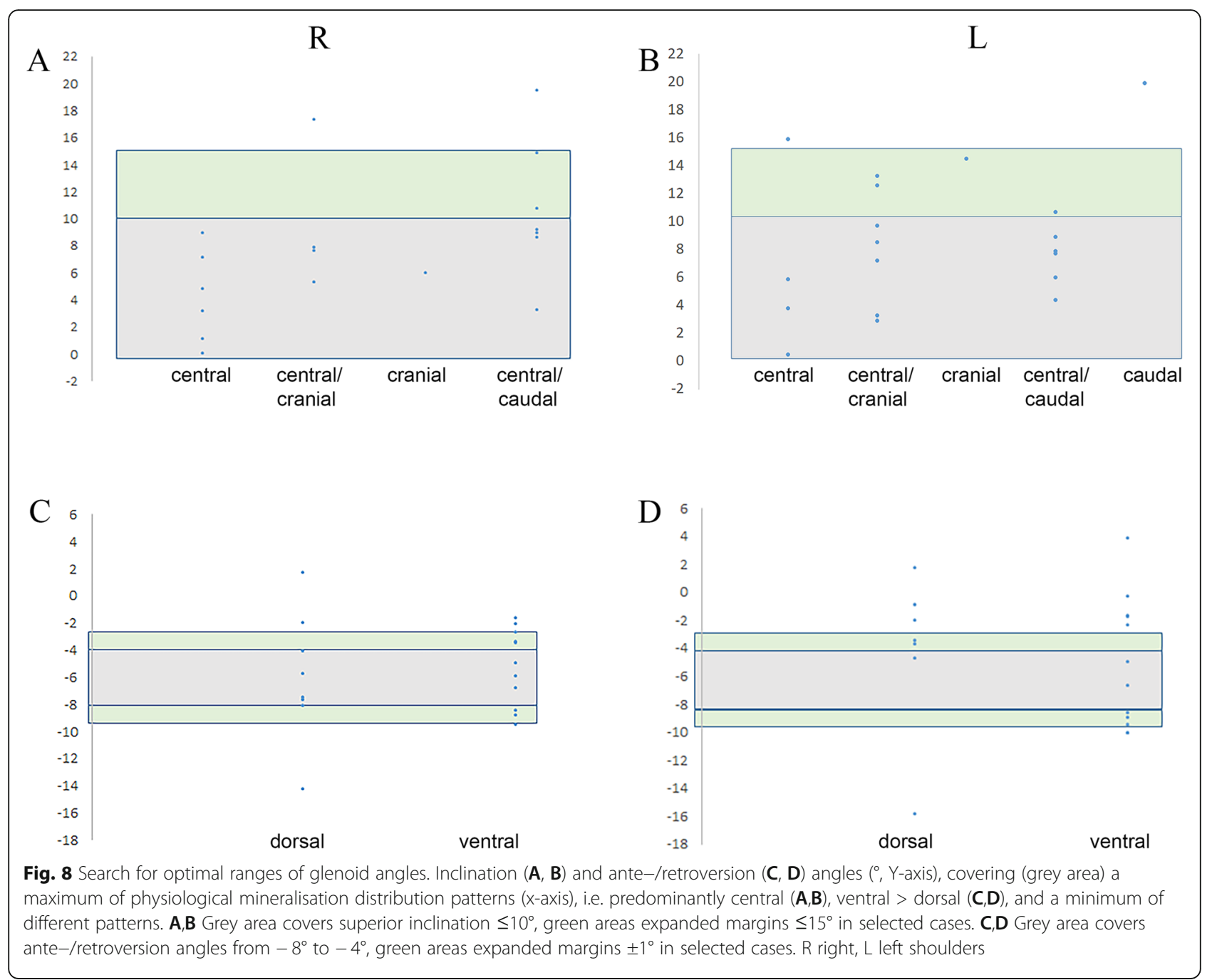

arthroplasty. In concentric glenoids, mineralisation was homogeneously distributed, with greater mineralisation in the central zone, whilst in the eccentric group, mineralisation distribution was inhomogeneous, predominantly in the posterior followed by the inferior zone. The authors concluded that CT-OAM may be effective to assist in preoperative planning for shoulder arthroplasty. In agreement, in three cases of inclination angles within our range, enlarged areas of mineralisation were found in the neighbourhood of damaged cartilage, particular on the glenoid rim, and diminished mineralisation within destroyed area, but also congruent spots were found. Enlarged areas of mineralisation as a sign of enhanced workload in cranial parts accompanied by morphological destruction in the caudal quadrants may be explained by pain avoidance. More data are required on pathological shoulder specimens, however first indication exists that CT-OAM may be suitable to announce early arthritic processes.
In the present study, we selected retroversion angles within a very narrow range, which may be the reason why they were more rarely found in glenoids with physiological mineralisation patterns. The mean ante -/retroversion angles from male and female donors combined were $-5.2^{\circ}$, which is similar to $-4^{\circ}$ in the control group in another study [43] using the Friedman method [13], and to $-3.8^{\circ}[6]$, and $-8.5^{\circ}$ using $3 \mathrm{D}-\mathrm{CT}$ reconstruction [10]. In a study comparing a new $2 \mathrm{D}$ method, retroversion angles of $-19^{\circ}$ were measured in the control group, whilst measurements according to Friedman revealed retroversion of $-1^{\circ}$ [41], similar to our previous study [35]. Thus, current findings point to a retroversion between $-8^{\circ}$ to $-4^{\circ}$ with a tolerance of \pm $1^{\circ}$ as physiological biomechanical situation, which is similar to previous work $[15,19,43,48]$. During surgery, $10-15^{\circ}$ of retroversion can be corrected using eccentric reaming of the glenoid according to Stephens et al. [48]. Similarly, Mizuno et al. [36] suggested a limit of $-10^{\circ}$ as 
surgical aim for correction using eccentric reaming. More data are required, also whether the range of the present study could be expanded, e.g. until $-10^{\circ}$ to $-3^{\circ}$, particularly in females. Data base is very limited, however, in both females with retroversion angles of $-10.1^{\circ}$, mineralisation distribution was physiological and osteoarthritis graded 0 and II, but in glenoids with higher retroversions in another female $\left(-14.3^{\circ},-15.9^{\circ}\right)$, dorsally enhanced mineralisation and osteoarthritis grades III and IV were found. We hypothesise whether the smaller glenoids in females may predispose to tolerate moderately higher retroversions. Nevertheless, higher retroversion angles predispose for dorsal shoulder subluxation and glenoid loosening [15], whereby Walch and coworkers [50] found retroversion of $24^{\circ}$ (versus $17.4^{\circ}$ ) to predispose for glenoid loss.

The data set has to be looked at with caution due to several limitations. First of all, the study was conducted on 19 body donors only. Further limitations of the study are that morphological evaluations are predominantly subjective and strongly rely on the experience of raters. Inter- and intra-observer variabilities were not measured. Furthermore, our post-mortem evaluation did not include functional changes or clinical reports. Since other omarthritis grading systems either included input from other radiological methods or functional examinations, we introduced our radiological omarthritis grading system as combination and adaptation of the Kellgren and Lawrence Score [25], the Samilson and Prieto classification [44], and the Larsen classification [30] since these are independent of aetiology and potential post-mortem changes. Elsharkawi and co-workers [11] recommended expansion of the commonly used Samilson and Prieto classification [44] especially for clinical and scientific purposes so that one advantage of our grading system is that it expands the primarily used Kellgren and Lawrence system [25] with respect to radiological signs including osteophyte formation and joint narrowing, but also includes inferior humeral head and glenoid exostosis as well as destructive abnormality and signs of erosions and allows for a more precise grading. A limitation of our system, however, is that due to $3 \mathrm{D}-\mathrm{CT}$ it does not include minor changes in the cartilage, as they are typical for initial stages of osteoarthritis, however this was partially compensated by the morphological investigations of the dissected specimens. In the present study, the critical shoulder angle CSA [4, 37] was outside the original scope of this work. Meanwhile for osteoarthritis, the inclination angle is proposed to be of lesser relevance than CSA $[1,53]$, whereby among the three components of CSA, glenoid inclination seems to have the largest impact regarding joint stability [5].

\section{Conclusion}

Although the data set is limited, in this elderly sexbalanced study cohort, the superior inclination angle between $0^{\circ}$ to $10^{\circ}-15^{\circ}$ and retroversion between $-9^{\circ}$ to $-3^{\circ}$ was associated with physiological mineralisation distribution of the glenoid. Enlarged areas of mineralisation appeared more frequently combined with discrete changes of the cartilage, but pronounced cartilage defects with decreased mineralisation and generally elevated mineralisation in the surrounding. More experience is required to expand the data set to other pathological shoulder specimens, however first indication exists that CT-OAM may be suitable to announce early osteoarthritic processes.

\section{Supplementary Information}

The online version contains supplementary material available at https://doi. org/10.1186/s12891-021-04660-4.

Additional file 1: Supplement 1 Sizes of glenoid and humeral head (millimetres, mm) measured by 3D-CT using landmarks depicted in Fig. 3. SD: Standard deviation.

\section{Acknowledgments \\ The authors gratefully acknowledge Marco Burkhard and Heinz Sonderegger, Institute of Anatomy, University of Zurich, for contribution to the establishment of the project. Further thank is due to Michael Thali, Head of Institute of Forensic Medicine, University of Zurich for excellent cooperation in the acquisition of $C T$ scans for teaching purposes. The authors gratefully acknowledge Mireille Toranelli and Sandra Blache, Division of Musculoskeletal Research, Department of Biomedicine, University of Basel, for introduction and technical contribution to CT-OAM.}

\section{Authors' contributions}

All authors have made substantial contributions to the study: EE, F-JR, KL, MMG and NS initiated the study. EE, FMB, KL, NS, SM and STS supervised study design and performance. EE, HK, MK, NS, PF, PG collected, analysed and interpreted the data. DG provided valuable technical contribution. EE and NS discussed the data and drafted the manuscript. F-JR, KL, MK, MM-G, $\mathrm{SB}$ and $\mathrm{OU}$ discussed the data and gave valuable input to manuscript writing. All authors read and approved the final draft of the manuscript.

\section{Funding}

The study was financially supported (salary and travel costs) by the Mäxi Foundation (to F-JR) and the Prof. Dr. med. Karl and Rena Theiler-Haag Foundation (travel costs and material, to $\mathrm{KL}$ ). The funding bodies had no role in the design of the study, collection, analysis or interpretation of the data, nor in writing the manuscript.

\section{Availability of data and materials}

The datasets analyzed during the current study are available from the corresponding author on reasonable request.

\section{Declarations}

Ethics approval and consent to participate

All body donors gave informed consent to research, which the authors gratefully acknowledge. The study was approved by the Zurich Cantonal Ethics Committee (KEK ZH-Nr. 2014-0303). The use of the human cadaveric material was according to the Federal Act on Research involving Human Beings (Human Research Act, HRA) of 1 January 2014 (https://www.admin.ch/ opc/de/classified-compilation/20061313/index.html) [20] and the Guidelines of the Swiss Academy of Medical Sciences, updated 2014 (http://www.samw. ch/de/Ethik/Richtlinien/Aktuell-gueltige-Richtlinien.html) [22, 23]. 


\section{Consent for publication}

Not applicable.

\section{Competing interests}

The authors declare that they have no competing interests.

\section{Author details}

${ }^{1}$ Institute of Evolutionary Medicine (IEM), University of Zurich, Zurich, Switzerland. ${ }^{2}$ Musculoskeletal Research, Department of Biomedicine, University of Basel, Basel, Switzerland. ${ }^{3}$ Division of Gross Anatomy, Institute of Anatomy, University of Zurich, Zurich, Switzerland. ${ }^{4}$ Anatomy, University of Fribourg, Fribourg, Switzerland. ${ }^{5}$ Medical Radiology Institute, Schulthess Clinic, Zurich, Switzerland. ${ }^{6}$ Clinic of Neuroradiology, University Hospital of Magdeburg, Magdeburg, Germany. ${ }^{7}$ Institute of Forensic Medicine, University of Zurich, Zurich, Switzerland. ${ }^{8}$ Department of Surgery, Limmattal Hospital, Zurich, Switzerland. ${ }^{9}$ Department of Orthopaedics, Balgrist University Hospital, Zurich, Switzerland. ${ }^{10}$ Department of Orthopaedic Surgery and Traumatology, University Hospital Fribourg, Fribourg, Switzerland. ${ }^{11}$ Institute of Anatomy, University of Bern, Bern, Switzerland.

\section{Received: 13 February 2021 Accepted: 25 August 2021}

\section{Published online: 05 October 2021}

\section{References}

1. Beeler S, Hasler A, Goetschi T, Meyer DC, Gerber C. Critical shoulder angle: acromial coverage is more relevant than glenoid inclination. J Orthop Res. 2019;37(1):205-10. https://doi.org/10.1002/jor.24053.

2. Boes $L$, Ellermann A. Arthrocopic diagnosis and classification of articular cartilage lesions. Deut Zeitschr Sportmed. 2003;54:181-3.

3. Boileau P, Gauci M-O, Wagner ER, Clowez G, Chaoui J, Chelli M, et al. The reverse shoulder arthroplasty angle: a new measurement of glenoid inclination for reverse shoulder arthroplasty. J Shoulder Elb Surg. 2019;28(7): 1281-90. https://doi.org/10.1016/j.jse.2018.11.074

4. Bouaicha S, Ehrmann C, Slankamenac K, Regan WD, Moor BK. Comparison of the critical shoulder angle in radiographs and computed tomography. Skelet Radiol. 2014;43(8):1053-6. https://doi.org/10.1007/s00256-014-1888-4.

5. Bouaicha S, Kuster RP, Schmid B, Baumgartner D, Zumstein M, Moor BK. Biomechanical analysis of the humeral head coverage, glenoid inclination and acromio-glenoidal height as isolated components of the critical shoulder angle in a dynamic cadaveric shoulder model. Clin Biomech. (Bristol, Avon). 2020;72:115-21. https://doi.org/10.1016/j.clinbiomech.2019.12. 003.

6. Bryce CD, Davison AC, Lewis GS, Wang L, Flemming DJ, Armstrong AD. Two-dimensional glenoid version measurements vary with coronal and sagittal scapular rotation. J Bone Joint Surg Am. 2010;92(3):692-9. https:// doi.org/10.2106/JBJS.I.00177.

7. Churchill RS, Brems JJ, Kotschi H. Glenoid size, inclination, and version: an anatomic study. J Shoulder Elb Surg. 2001;10(4):327-32. https://doi.org/10.1 067/mse.2001.115269.

8. Daggett M, Werner B, Collin P, Gauci MO, Chaaoui J, Walch G. Correlation between glenoid inclination and critical shoulder angle: a radiographic and computed tomography study. J Shoulder Elb Surg. 2015;24(12):1948-53. https://doi.org/10.1016/j.jse.2015.07.013.

9. Dingemanse WB, Gielen IMLV, van Bree HJJ, Müller-Gerbl M, Krstić NE, Mitrović MB, et al. Spatial subchondral bone density reflecting joint loading of the talus in different Canidae. Vet Comp Orthop Traumatol. 2019;32(03): 207-14. https://doi.org/10.1055/s-0039-1685511.

10. DiStefano JG, Park AY, Nguyen TQD, Diederichs G, Buckley JM, Montgomery WH. Optimal screw placement for base plate fixation in reverse total shoulder arthroplasty. J Shoulder Elb Surg. 2011;20(3):467-76. https://doi. org/10.1016/j.jse.2010.06.001

11. Elsharkawi M, Cakir B, Reichel H, Kappe T. Reliability of radiologic glenohumeral osteoarthritis classifications. J Shoulder Elb Surg. 2013;22(8): 1063-7. https://doi.org/10.1016/j.jse.2012.11.007.

12. Favard L, Berhouet J, Walch G, Chaoui J, Lévigne C. Superior glenoid inclination and glenoid bone loss. Definition, assessment, biomechanical consequences, and surgical options. Orthopäde. 2017;46(12):1015-21. https://doi.org/10.1007/s00132-017-3496-1.

13. Friedman RJ, Hawthorne KB, Genez BM. The use of computerizedtomography in the measurement of glenoid version. J Bone Joint Surg Am. 1992;74A:1032-7.
14. Gascho D, Thali MJ, Niemann T. Post-mortem computed tomography: technical principles and recommended parameter settings for highresolution imaging. Med Sci Law. 2018;58(1):70-82. https://doi.org/10.1177/ 0025802417747167

15. Gates S, Sager B, Khazzam M. Preoperative glenoid considerations for shoulder arthroplasty: a review. Effort Open Rev Shoulder Elbow. 2020;5(3): 126-37. https://doi.org/10.1302/2058-5241.5.190011.

16. Gregory TM, Sankey A, Augereau B, Vandenbussche E, Amis A, Emery R, et al. Accuracy of glenoid component placement in total shoulder arthroplasty and its effect on clinical and radiological outcome in a retrospective, longitudinal, monocentric open study. PLoS One. 2013;8(10): e75791. https://doi.org/10.1371/journal.pone.0075791.

17. Ho JC, Ricchetti ET, lannotti JP. Central-peg radiolucency progression of an all-polyethylene glenoid with hybrid fixation in anatomic total shoulder arthroplasty is associated with clinical failure and reoperation. J Shoulder Elb Surg. 2021;30(5):1068-77. https://doi.org/10.1016/j.jse.2020.07.039.

18. Hoechel S, Zwimpfer TA, Toranelli M, Mueller-Gerbl M. The adaptation of the bony microstructure of the human glenoid cavity as a result of longterm biomechanical loading. Surg Radiol Anat. 2019:41(4):401-8. https://doi. org/10.1007/s00276-019-02190-2.

19. Hoenecke HR, Hermida JC, Flores-Hernandez C, D'Lima DD. Accuracy of CTbased measurements of glenoid version for total shoulder arthroplasty. J Shoulder Elb Surg. 2010;19(2):166-71. https://doi.org/10.1016/j.jse.2009.08. 009.

20. https://www.admin.ch/opc/de/classified-compilation/20061313/index.html. Accessed 23 Sep 2021.

21. http://www.anatomy.uzh.ch/de/koerperspende.html. Accessed 23 Sep 2021.

22. http://www.samw.ch/de/Ethik/Richtlinien/Aktuell-gueltige-Richtlinien.html. Accessed 23 Sep 2021

23. https://www.ssahe.ch/files/snga/empfehlungen_samw leichen_leichenteile. pdf. Accessed 23 Sep 2021

24. lannotti JP, Weiner S, Rodriguez E, Subhas N, Patterson TE, Jun BJ, et al. Three-dimensional imaging and templating improve glenoid implant and positioning. J Bone Joint Surg. 2015;97(8):651-8. https://doi.org/10.2106/ JBJS.N.00493.

25. Kellgren J, Lawrence J. Radiological assessment of osteoarthritis. Ann Rheumatic Dis. 1957;16(4):494-502. https://doi.org/10.1136/ard.16.4.494.

26. Knowles NK, Carroll M, Keener J, Ferreira L, Athwal G. A comparison of normal and osteoarthritic humeral head size and morphology. J Shoulder Elb Surg. 2016;25(3):502-9. https://doi.org/10.1016/j.jse.2015.08.047.

27. Knowles NK, Ferreira L, Athwal GS. Premorbid retroversion is significantly greater in type B2 glenoids. J Shoulder Elb Surg. 2016;25(7):1064-8. https:// doi.org/10.1016/j.jse.2015.11.002.

28. Kraljević M, Zumstein V, Huegli R, Mueller-Gerbl M. A comparison of subchondral bone mineralization between the glenoid cavity and the humeral head on 57 cadaverous shoulder joints. Surg Radiol Anat. 2013; 35(4):295-300. https://doi.org/10.1007/s00276-012-1034-8.

29. Laedermann A, Gueorguiev B, Charbonnier C, Stimec BV, Fasel JHD, Zderic I, et al. Scapular notching on kinematic simulated range of motion after Reverse Shoulder Arthroplasty is not the result of impingement in adduction. Medicine (Baltimore). 2015;94:e1615. https://doi.org/10.1097/MD. 0000000000001615

30. Larsen A, Dale K, Eek M. Radiographic evaluation of rheumatoid arthritis and related conditions by standard reference films. Acta Radiol Diagn. 1977; 18(4):481-91. https://doi.org/10.1177/028418517701800415.

31. Levy J, Kurowicki J, Triplet J, Niedzielak T, Disla S. Accuracy of glenoid version and inclination: a comparison of surgicare and blueprint surgical planning software programs. Bone Joint Surg. 2017;99:91.

32. Madry H, Van Dijk CN, Mueller-Gerbl M. The basic science of the subchondral bone. Knee Surg Sports Traumatol Arthrosc. 2010;18(4):419-33. https://doi.org/10.1007/s00167010-1054-z.

33. Mariaux S, Obrist R, Farron A, Becce F, Terrier A. Is preoperative glenoid bone mineral density associated with aseptic glenoid implant loosening in anatomic total shoulder arthroplasty? BMC Musculoskelet Disord. 2021;22(1): 49. https://doi.org/10.1186/s12891-020-03892-0.

34. Martin R, Saller K. Lehrbuch der Anthropologie in systematischer Darstellung mit besonderer Berücksichtigung der anthropologischen Methoden. Stuttgart: Gustav Fischer Verlag; 1957.

35. Mathews S, Burkhard M, Serrano N, Link K, Häusler M, Frater N, et al. Glenoid morphology in light of anatomical and reverse total shoulder arthroplasty: a dissection-and 3D-CT-based study in male and female body donors. BMC 
Musculoskelet Disord. 2017;18(1):9. https://doi.org/10.1186/s12891-016-13 73-4.

36. Mizuno N, Denard PJ, Walch G. Reverse total shoulder arthroplasty for primary glenohumeral osteoarthritis in patients with a biconcave glenoid. J Bone Joint Surg. 2013;95(14):1297-304. https://doi.org/10.2106/JBJS.L.00820.

37. Moor BK, Bouaicha S, Rothenfluh DA, Sukthankar A, Gerber C. Is there an association between the individual anatomy of the scapula and the development of rotator cuff tears or osteoarthritis of the glenohumeral joint? Bone Joint J. 2013;95(7):935-41. https://doi.org/10.1302/0301-620X. 95B7.31028.

38. Müller-Gerbl M, Putz R, Hodapp N, Schulte E, Wimmer B. Computed tomography-osteoabsorptiometry for assessing the density distribution of subchondral bone as a measure of long-term mechanical adaptation in individual joints. Skelet Radiol. 1989;18(7):507-12. https://doi.org/10.1007/ bf00351749.

39. Ozel O, Hudek R, Abdrabou MS, Werner BS, Gohlke F. The implications of the glenoid angles and rotator cuff status in patients with osteoarthritis undergoing shoulder arthroplasty. BMC Musculoskelet Disord. 2020;21(1): 668. https://doi.org/10.1186/s12891-020-03690-8.

40. Poilliot A, Doyle T, Kurosawa D, Toranelli M, Zhang M, Zwirner J, et al. Computed tomography osteoabsorptiometry-based investigation on subchondral bone plate alterations in sacroiliac joint dysfunction. Sci Rep. 2021;21(1):8652. https://doi.org/10.1038/s41598-021-88049-2.

41. Poon PC, Ting FS. A 2-dimensional glenoid vault method for measuring glenoid version on computed tomography. J Shoulder Elb Surg. 2012;21(3): 329-35. https://doi.org/10.1016/j.jse.2011.04.006.

42. Prescher A. Anatomical basics, variations, and degenerative changes of the shoulder joint and shoulder girdle. Eur J Radiol. 2000;35(2):88-102. https:// doi.org/10.1016/50720-048x(00)00225-4.

43. Privitera DM, Siegel EJ, Miller LR, Sinz NJ, Higgins LD. Glenoid version and its relationship to glenohumeral instability and labral tears. J Shoulder Elb Surg. 2016;25(7):1056-63. https://doi.org/10.1016/j.jse.2015.11.013.

44. Samilson R, Prieto V. Dislocation arthropathy of the shoulder. J Bone Joint Surg Am. 1983;65(4):456-60. https://doi.org/10.2106/00004623-19836504000005.

45. Schulz CU, Pfahler M, Anetzberger HM, Becker CR, Mueller-Gerbl M, Refior $\mathrm{HJ}$. The mineralization patterns at the subchondral bone plate of the glenoid cavity in healthy shoulders. J Shoulder Elb Surg. 2002;11(2):174-81. https://doi.org/10.1067/mse.2002.121635.

46. Simon P, Gupta A, Pappou I, Santoni BG, Inoue N, Frankle MA. Glenoid subchondral bone density distribution in male total shoulder arthroplasty subjects with eccentric and concentric wear. J Shoulder Elb Surg. 2015;24(3): 416-24. https://doi.org/10.1016/j.jse.2014.06.054.

47. Slattery C, Kweon CY. Classification in brief: Outerbridge classification of chondral lesions. Clin Orthop Relat Res. 2018;476(10):2101-4. https://doi. org/10.1007/s11999.0000000000000255.

48. Stephens SP, Paisley KC, Jeng J, Dutta AK, Wirth MA. Shoulder arthroplasty in the presence of posterior glenoid bone loss. J Bone Joint Surg Am. 2015; 97(3):251-9. https://doi.org/10.2106/JBJS.N.00566.

49. Von Eisenhart-Rothe R, Mueller-Gerbl M, Wiedemann E, Englmeier K-H, Graichen $\mathrm{H}$. Functional malcentering of the humeral head and asymmetric long-term stress on the glenoid: potential reasons for glenoid loosening in total shoulder arthroplasty. J Shoulder Elb Surg. 2008;17(5):695-702. https:// doi.org/10.1016/j.jse.2008.02.008.

50. Walch G, Moraga C, Young A, Castellanos-Rosas J. Results of anatomic nonconstrained prosthesis in primary osteoarthritis with biconcave glenoid. J Shoulder Elb Surg. 2012;21(11):1526-33. https://doi.org/10.1016/j.jse.2 011.11.030.

51. Weinstein DM, Bucchieri JS, Pollock RG, Flatow EL, Bigliani LU. Arthroscopic debridement of the shoulder for osteoarthritis. J Arthroscopic Related Surg. 2000;16(5):471-6. https://doi.org/10.1053/jars.2000.5042.

52. Wolfensberger $F$, Grüninger $P$, Dietrich $M$, Völlink $M$, Benninger E, Schläppi $M$, et al. Reverse shoulder arthroplasty for complex fractures of the proximal humerus in elderly patients: impact on the level of independency, early function, and pain medication. J Shoulder Elb Surg. 2017;26(8):1462-8. https://doi.org/10.1016/j.jse.2017.01.021.

53. Wong AS, Gallo L, Kuhn JE, Carpenter JE, Hughes RE. The effect of glenoid inclination on superior humeral head migration. J Shoulder Elb Surg. 2003; 12(4):360-4. https://doi.org/10.1016/S1058-2746(03)00026-0.

54. Yahaya I, Wright T, Babatunde OO, Corp N, Helliwell T, Dikomitis L, et al. Prevalence of osteoarthritis in lower middle- and low-income countries: a systematic review and meta-analysis. Rheumatol Int. 2021;41(7):1221-31. https://doi.org/10.1007/s00296-021-04838-y.

55. Zaid MB, Young NM, Pedoia V, Feeley BT, Ma CB, Lansdown DA. Anatomic shoulder parameters and their relationship to the presence of degenerative rorator cuff tears and glenohumeral osteoarthritis: a systematic review and meta-analysis. J Shoulder Elb Surg. 2019;28(12):2457-66. https://doi.org/10.1 016/j.jse.2019.05.008

56. Zumstein V, Kraljevic M, Huegli R, Mueller-Gerbl M. Mineralisation patterns in the subchondral bone plate of the humeral head. Int Orthop. 2011;35(12): 1813-9. https://doi.org/10.1007/s00264-011-1308-5.

57. Zumstein V, Kraljevic M, Conzen A, Hoechel S, Mueller-Gerbl M. Thickness distribution of the glenohumeral joint cartilage: a quantitative study using computed tomography. Surg Radiol Anat. 2014;36(4):327-31. https://doi. org/10.1007/s00276-013-1221-2.

58. Zumstein V, Kraljevic M, Hoechel S, Conzen A, Nowakowski AM, MuellerGerbl M. The glenohumeral joint - a mismatching system? A morphological analysis of the cartilaginous and osseous curvature of the humeral head and the glenoid cavity. J Orthop Surg Res. 2014;9(1):34. https://doi.org/10.11 86/1749-799X-9-34.

\section{Publisher's Note}

Springer Nature remains neutral with regard to jurisdictional claims in published maps and institutional affiliations.

\section{Ready to submit your research? Choose BMC and benefit from:}

- fast, convenient online submission

- thorough peer review by experienced researchers in your field

- rapid publication on acceptance

- support for research data, including large and complex data types

- gold Open Access which fosters wider collaboration and increased citations

- maximum visibility for your research: over $100 \mathrm{M}$ website views per year

At BMC, research is always in progress.

Learn more biomedcentral.com/submissions 